\title{
Long-term benefit of redo sympathetic renal denervation in a patient with resistant hypertension
}

\author{
Tomasz Tokarek ${ }^{1,2}$, Renata Rajtar-Salwa ${ }^{1}$, Łukasz Rzeszutko ${ }^{1}$, Stanisław Bartuś ${ }^{1}$ \\ ${ }^{1}$ Department of Cardiology and Cardiovascular Interventions, University Hospital, Krakow, Poland \\ ${ }^{2}$ Department of Intensive Care and Perioperative Medicine, Jagiellonian University Medical College, Krakow, Poland
}

Adv Interv Cardiol 2021; 17, 2 (64): 239-241

DOI: https://doi.org/10.5114/aic.2021.107513

Sympathetic renal denervation (RDN) has been demonstrated as a potential treatment option for patients with resistant hypertension [1]. Despite discouraging results after the SYMPLICITY HTN-3 trial several techniques and catheters were introduced to the market and data confirming adequate and effective denervation are growing [1, 2]. In current guidelines invasive methods are not recommended as routine treatment of resistant hypertension [3, 4]. However, a highly selected group of patients not responding to aggressive medical treatment might benefit from this method [1-4].

A 35-year-old Caucasian man with a history of resistant hypertension with concomitant persistent headaches and nonspecific chest pain was admitted to the Department of Cardiology and Cardiovascular Interventions, University Hospital in Krakow. The patient was a heavy smoker; despite cigarette cessation increased blood pressure (BP) was maintained in both home and office measurements. Potential etiologies of secondary hypertension were excluded. 24-hour ambulatory blood pressure monitoring (ABPM) revealed increased mean blood pressure (mean value: 24 h 153/110 mm Hg; during day 162/96 mm Hg; during night 128/74 mm Hg) (Figure $1 \mathrm{~A}$ ). Antihypertensive therapy with five antihypertensive drugs including a loop diuretic was insufficient. The patient was referred for RDN. The procedure was conducted with the Symplicity Spyral multi-electrode renal denervation catheter (Medtronic, Minneapolis, MN, USA) using a femoral approach. Radiofrequency energy applications covered all the circuit of the artery without any complications. After an uneventful recovery a significant reduction in both systolic and diastolic BP was observed. The patient was discharged with 4 antihypertensive drugs with optimal BP control during 6-month follow-up (mean value: 24 h 125/72 mm Hg; during day 130/78 mm Hg; during night 115/61 mm Hg) (Figure $1 \mathrm{~B}$ ). Renal function was unchanged. Despite an uninterrupted medication regimen refractory headaches and chest pain with hypertension were observed after 12 months from RDN. Multislice computed tomography excluded coronary artery disease. Treatment escalation with six antihypertensive drugs was introduced. Clinical evaluation with ABPM again revealed high mean BP (mean value: 24 h 157/100 mm Hg; during day 164/104 mm Hg; during night 146/91 mm Hg) (Figure $1 \mathrm{C}$ ). In light of ineffective BP control the patient was scheduled for redo RDN. A second procedure was performed via the femoral artery using the Symplicity Spyral system (Medtronic, Minneapolis, MN, USA). Ablation of 360 degrees of both renal arteries was conducted. No periprocedural complications were observed. There was no biochemical deterioration of kidney function. On discharge from hospital antihypertensive therapy composed of six full-dose drugs (including diuretic) was recommended. During follow-up visits after 1, 6 and 12 months doses of antihypertensive drugs were gradually reduced, satisfactory control of BP was maintained during 12-month observation (mean value: 24 h 119/69 mm Hg; during day 122/74 mm Hg; during night 115/60 mm Hg) (Figure $1 \mathrm{D}$ ).

\section{Conflict of interest}

The authors declare no conflict of interest.

\section{Corresponding author:}

Tomasz Tokarek MD, Department of Cardiology and Cardiovascular Interventions, University Hospital, 2 Jakubowskiego St, $30-688$ Krakow, Poland, phone: +48 669638 498, e-mail: tomek.tokarek@gmail.com

Received: 20.01.2021, accepted: 11.03.2021. 
A

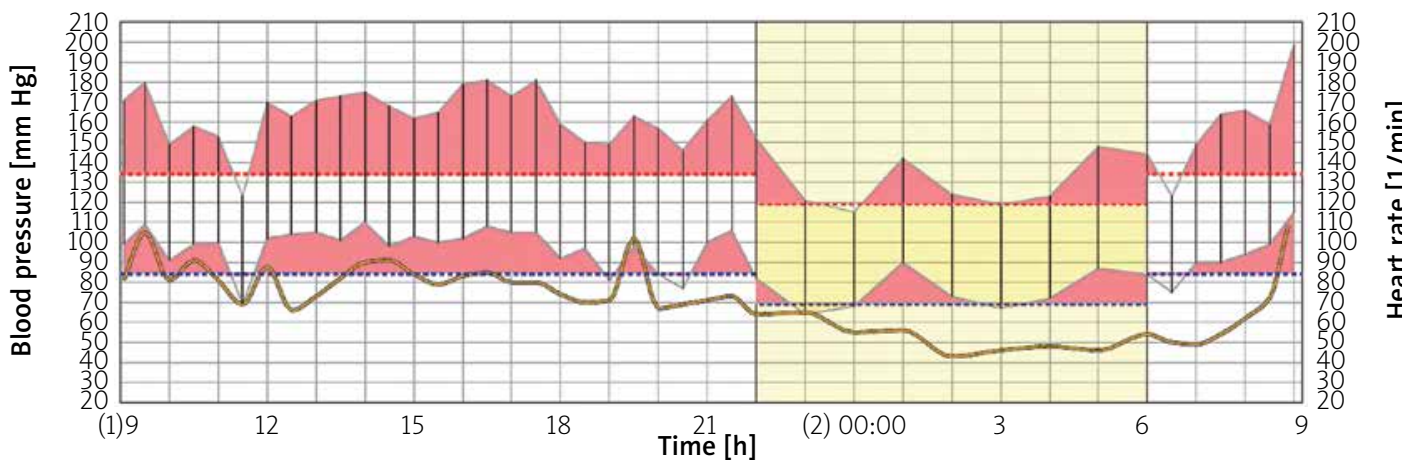

B

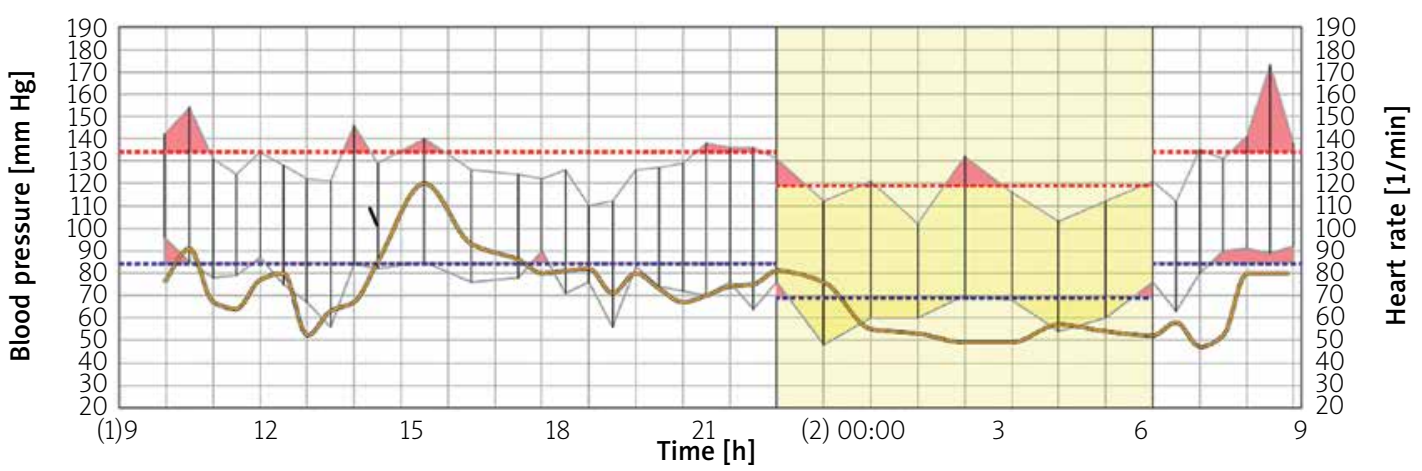

C

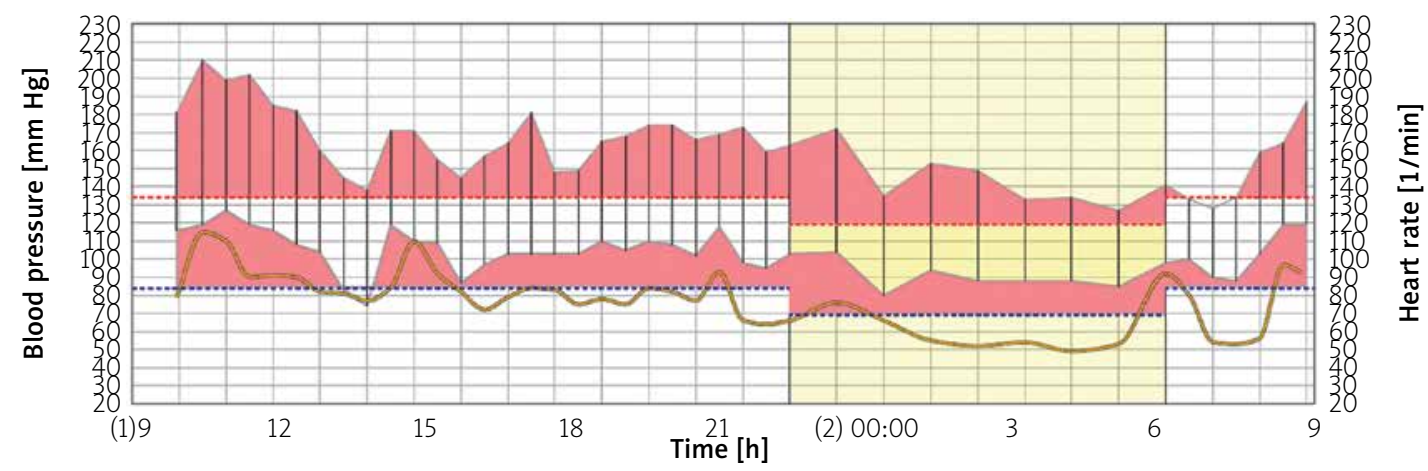

D

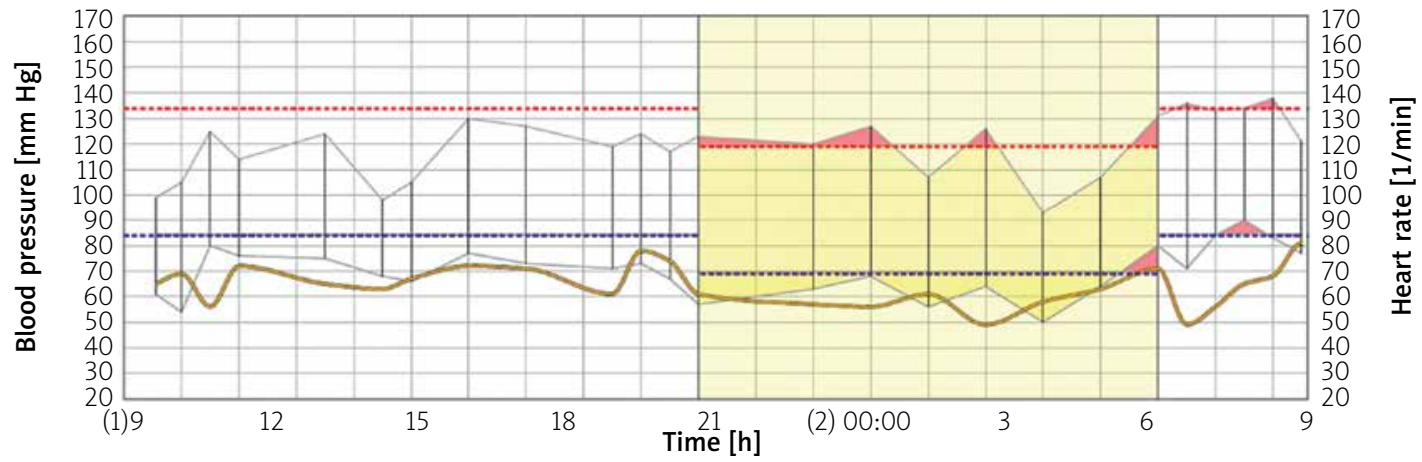

Figure 1. 24-hour ambulatory blood pressure monitoring before first sympathetic renal denervation (A), 6 months after first procedure (B), 12 months after first procedure (C) and 12 months after second sympathetic renal denervation (D). Blue and red dots represent normal range for 24-hour ambulatory blood pressure monitoring. Yellow line represents heart rate 


\section{References}

1. Versaci F, Sciarretta S, Scappaticci M, et al. Renal arteries denervation with second generation systems: a remedy for resistant hypertension? Eur Heart J 2020; 22 (Suppl L): L160-5.

2. Maqsood MH, Rubab K, Anwar F, et al. A systematic review of randomized controlled trials comparing renal sympathetic denervation versus sham procedure for the management of uncontrolled hypertension. J Cardiovasc Pharmacol 2021: 77: 153-8.

3. Williams B, Mancia G, Spiering W, et al. 2018 ESC/ESH Guidelines for the management of arterial hypertension. Eur Heart $J$ 2018; 39: 3021-104.

4. Tykarski A, Filipiak KJ, Januszewicz A, et al. Zasady postępowania w nadciśnieniu tętniczym - 2019 rok. Wytyczne Polskiego Towarzystwa Nadciśnienia Tętniczego. Nadciśnienie Tętnicze w Praktyce 2019; 5: 1-86. 